\title{
A Chemosensor Array for the Colorimetric Identification of 20 Natural Amino Acids
}

\author{
Andrey Buryak and Kay Severin* \\ Institut des Sciences et Ingénierie Chimiques, École Polytechnique Fédérale de Lausanne (EPFL), \\ CH-1015 Lausanne, Switzerland
}

Received December 20, 2004; E-mail: kay.severin@epfl.ch

Indicator displacement assays (IDAs) have been successfully applied to sense a variety of analytes such as citrate, ${ }^{1}$ heparin, ${ }^{2}$ phosphates, ${ }^{3}$ carbonate, ${ }^{4}$ amino acids, ${ }^{5}$ and peptides $^{5 \mathrm{c}, 6}$ among others. ${ }^{7}$ The basis of IDAs are chemosensors in which the receptor units are connected via noncovalent interactions to signaling units (indicators). Upon addition of a substrate, the indicators are replaced, resulting in a change of their optical properties. This type of supramolecular approach toward sensing has the advantage that it is very simple to implement. Furthermore, it is possible to modulate the sensitivity as well as the selectivity of the assay by variation of the receptor-indicator ratio ${ }^{8}$ or the sensing conditions (e.g., $\mathrm{pH}$, see below). Thus far, the focus has been on constructing highly selective IDAs using carefully designed receptor units with high specificity for a certain analyte. ${ }^{7}$ The utilization of IDAs for multianalyte sensing ${ }^{9}$ or for array technologies ${ }^{10,11}$ is largely unexplored. In the following we describe an IDA-based sensor array, in which the respective sensors are assembled from commercially available building blocks. This array allows the differentiation of 20 natural amino acids with high fidelity using UV/vis spectroscopy in combination with a multivariate analysis.

Over the last 5 years, a number of IDA-based sensors for amino acids have been described. ${ }^{5}$ Selectivity was mainly achieved by using receptors which are able to recognize a certain functional group of an amino acid side chain (e.g., imidazole of His, thiol of Cys, or carboxylate of Asp or Glu). To distinguish simple, nonfunctionalized amino acids such as Ala or Val, however, a single-sensor approach would be difficult to realize because of the lack of sufficiently specific receptors. We therefore decided to investigate whether an array-based approach would be suitable for achieving the required selectivity. ${ }^{12,13}$ The organometallic $\mathrm{Cp} * \mathrm{Rh}$ complex 1 was employed as the receptor unit for our IDAs (Scheme 1). This complex is soluble in water, not sensitive to air, displays relatively fast exchange kinetics for the three facial coordination sites opposite to the $\mathrm{Cp}^{*}$ ligand, and shows a high affinity for amino acids and peptides. ${ }^{14} \mathrm{~A}$ first application of $\mathbf{1}$ in IDAs for His- and Met-containing peptides has recently been decribed. ${ }^{6}$ As the indicators, the dyes gallocyanine (2), xylenol orange (3), and calcein blue (4) were employed. These dyes bind to the $\mathrm{Cp} * \mathrm{Rh}$ complex with a strong change in color and with a variable affinity in the low micromolar range (see Supporting Information). The binding constants of the amino acids to the $\mathrm{Cp} * \mathrm{Rh}$ complex were found to be in the same range as those of the dyes, resulting in a real competition situation for at least one dye-amino acid combination. A key component of our sensor array was the utilization of a variable $\mathrm{pH}$. The $\mathrm{pH}$ was expected to change the selectivity of the IDAs because the relative binding affinity of a given dye-amino acid pair depends on the $\mathrm{pH} .{ }^{15}$

The procedure for the colorimetric identification of 20 natural amino acids using an IDA-based assay is summarized in Scheme 1. First, the UV/vis response at $750 \mathrm{~nm}$ of an IDA composed of $\mathbf{1}$
Scheme 1. Colorimetric Identification of 20 Natural Amino Acids Using IDA Arrays Composed of Receptor 1 and the Indicators 2-4 at Different pHs
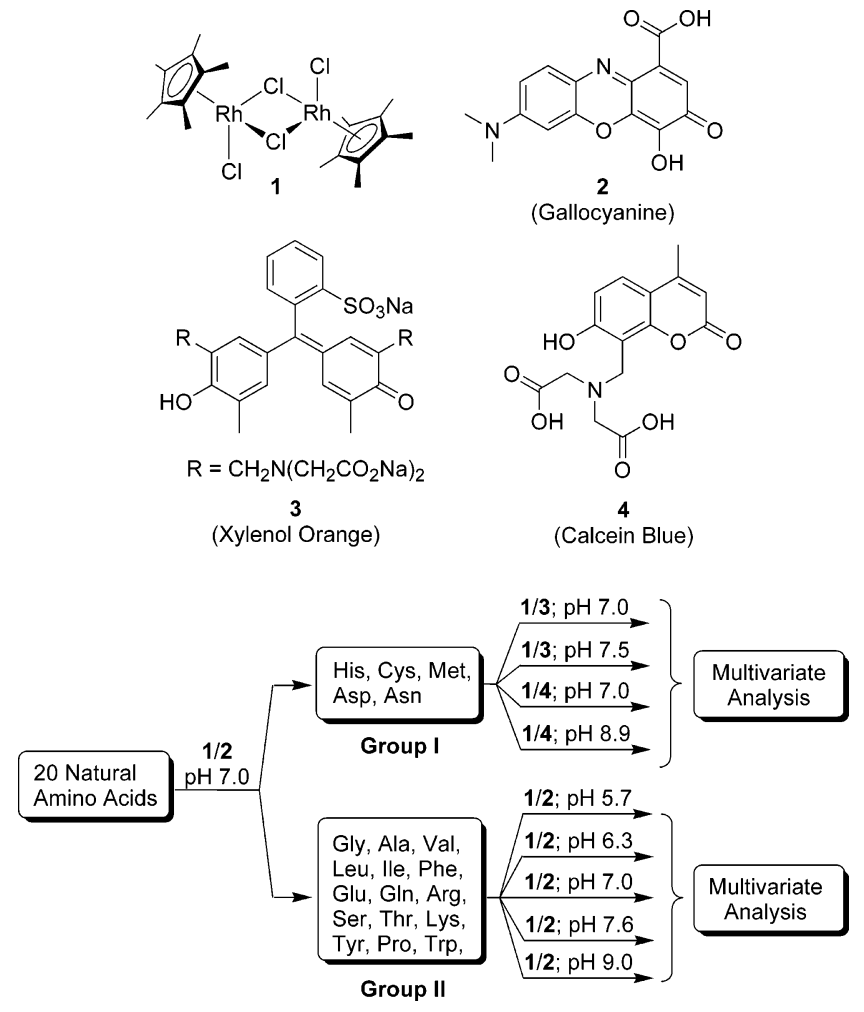

(50 $\mu \mathrm{M})$ and gallocyanine (2) $(100 \mu \mathrm{M})$ was used to classify the amino acids $(750 \mu \mathrm{M})$ into a high- and a low-affinity group. The high-affinity group consists of His, Cys, Met, Asp, and Asn for which a nearly quantitative replacement of the dye $\mathbf{2}$ from the rhodium complex was observed $(\triangle A(750 \mathrm{~nm})<0.06) .{ }^{16}$ The remaining 15 amino acids lead to a partial replacement of the dye $(0.55>\Delta A(750 \mathrm{~nm})>0.06)$ and constitute the second group. After this separation, each member of the first group was analyzed by four IDAs (two different dyes, 3 and $\mathbf{4}$, and two different $\mathrm{pH}$ values), and each member of the second group was analyzed by five IDAs (indicator 2 at five different $\mathrm{pH}$ values). ${ }^{17}$ In each case, the analysis was repeated 12 times with all data being gathered in a highly parallel fashion using a microplate reader.

The data for three selected amino acids of group II (Ala, Phe, Pro) are shown in Figure 1. Despite the fact that these amino acids do not possess additional functional groups on their side chains, a unique absorption pattern was obtained. To evaluate whether this "fingerprint" can be used for the identification of the amino acids, a linear discriminant analysis (LDA) was performed. ${ }^{18}$ 


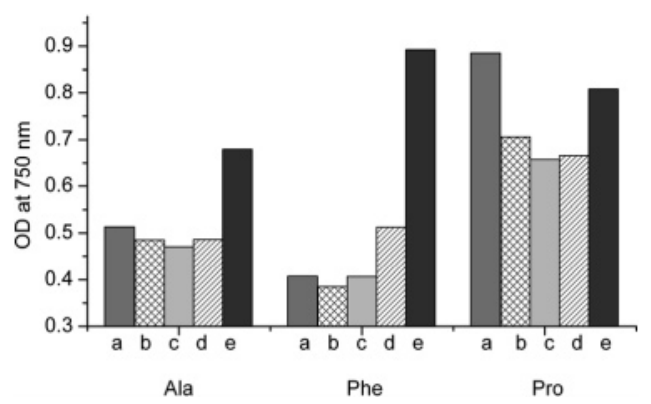

Figure 1. Absorbance at $750 \mathrm{~nm}$ for mixtures containing the dye 2 (100 $\mu \mathrm{M})$, the receptor $1(50 \mu \mathrm{M})$, and the respective amino acids $(750 \mu \mathrm{M})$ determined at five different $\mathrm{pH}$ values: 5.7 (a), 6.3 (b), 7.0 (c), 7.6 (d), and 9.0 (e) (MES, phosphate or CHES buffer, $85 \mathrm{mM}$ ).

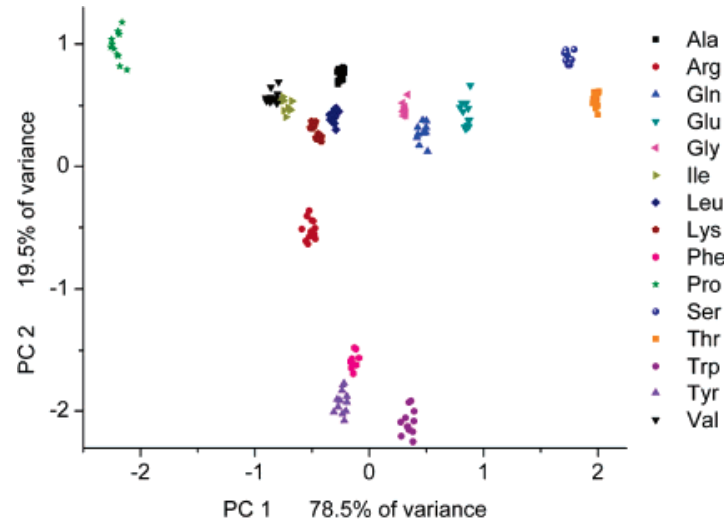

Figure 2. Score plot for the identification of the amino acids of group II.

The predictive ability of our sensor array was determined by a cross-validation routine, in which randomly one measurement was omitted. The remaining data were used as the training set for the LDA, and the omitted observation was classified. The data of group I and II were treated separately. For group I, all data were assigned accurately, and for group II, 1 misclassification out of 180 observations was obtained ( $99.4 \%$ accuracy). If only $50 \%$ of the data were used as the training set, group I was still assigned with $100 \%$ accuracy. For group II, 174 out of 180 observations were classified correctly (96.7\% accuracy). The amino acids, which gave rise to these occasional mismatches were valine and isoleucine.

To visualize the clustering of the data, a principal component analysis (PCA) was performed. ${ }^{18}$ The results for the amino acids of group II are depicted in Figure 2. The data appear in wellseparated groups with the only overlap found for valine and isoleucine. To some extent, chemical and structural similarities are reflected by the relative position of the group. The data of the hydroxy amino acids serine and threonine, for example, are positioned in proximity to each other as well as the data for the aromatic amino acids phenylalanine, tyrosine, and tryptophan. The only cyclic amino acid, proline, is well separated from the rest.

The results described above demonstrate the analytical power of IDAs performed in an array format. Closely related analytes such as leucine and isoleucine are clearly distinguishable, a result which would be very difficult to achieve with a classical one sensor-one analyte approach. The IDA array used for our analysis is very easy to build because the only requirement is mixing of commercially available building blocks at different pHs. It appears likely that similar assays can be constructed for the analysis of more complex analytes such as peptides and proteins. Research along these lines is currently being pursued in our laboratory.

Acknowledgment. The work was supported by a Ph.D. fellowship from the doctoral program of the EPFL (A.B.). We thank Prof. Kai Johnsson (EPFL) for his support with the microplate reader.

Supporting Information Available: UV/visible titration data for the reaction of receptor $\mathbf{1}$ with the indicators $\mathbf{2 - 4}$, experimental procedures for the IDAs, a description of the data analysis, and a score plot for the amino acids of group I. This material is available free of charge via the Internet at http://pubs.acs.org.

\section{References}

(1) (a) McCleskey, S. C.; Metzger, A.; Simmons, C. S.; Anslyn, E. V Tetrahedron 2002, 58, 621-628. (b) Metzger, A.; Anslyn, E. V. Angew. Chem., Int. Ed. 1998, 37, 649-652.

(2) Zhong, Z.; Anslyn, E. V. J. Am. Chem. Soc. 2002, 124, 9014-9015.

(3) (a) Zhang, T.; Anslyn, E. V. Tetrahedron 2004, 60, 11117-11124. (b) Hanshaw, R. G.; Hilkert, S. M.; Jiang, H.; Smith, B. D. Tetrahedron Lett. 2004, 45, 8721-8724. (c) Tobey, S. L.; Anslyn, E. V. Org. Lett. 2003, 5 , 2029-2031. (d) Zhong, Z.; Anslyn, E. V. Angew. Chem., Int. Ed. 2003, 42, 3005-3008. (e) Han, M. S.; Kim, D. H. Angew. Chem., Int. Ed. 2002, 41, 3809-3811. (f) Fabbrizzi, L.; Marcotte, N.; Stomeo, F.; Taglietti, A. Angew. Chem., Int. Ed. 2002, 41, 3811-3814. (g) Niikura, K.; Metzger, A.; Anslyn, E. V. J. Am. Chem. Soc. 1998, 120, 8533-8534.

(4) Fabbrizzi, L.; Leone, A.; Taglietti, A. Angew. Chem., Int. Ed. 2001, 40, $3066-3069$

(5) (a) Bonizzoni, M.; Fabbrizzi, L.; Piovani, G.; Taglietti, A. Tetrahedron 2004, 60, 11159-11162. (b) Han, M. S.; Kim, D. H. Tetrahedron 2004, 60, 11251-11257. (c) Chow, C.-F.; Chiu, B. K. W.; Lam, M. H. W. Wong, W.-Y. J. Am. Chem. Soc. 2003, 125, 7802-7803. (d) Hortalá, M A.; Fabbrizzi, L.; Marcotte, N.; Stomeo, F.; Taglietti, A. J. Am. Chem. Soc. 2003, 125, 20-21. (e) Deam, K. E. S.; Klein, G.; Renaudet, O; Reymond, J.-L. Bioorg. Med. Chem. Lett. 2003, 13, 1653-1656. (f) AitHaddou, H.; Wiskur, S. L.; Lynch, V. M.; Anslyn, E. V. J. Am. Chem Soc. 2001, 123, 11296-11297. (g) Klein, G.; Reymond, J.-L. Angew. Chem., Int. Ed. 2001, 40, 1771-1773.

(6) Buryak, A.; Severin, K. Angew. Chem. Int. Ed. 2004, 43, 4771-4774.

(7) For reviews, see: (a) Wiskur, S. L.; Aitt-Haddou, H.; Lavigne, J. J.; Anslyn, E. V. Acc. Chem. Res. 2001, 34, 963-972. (b) Fabbrizzi, L.; Licchelli, M.; Taglietti, A. Dalton Trans. 2003, 3471-3479. (c) Sukasai, C. Tuntulani, T. Chem. Soc. Rev. 2003, 32, 192-202.

(8) Piatek, A. M.; Bomble, Y. J.; Wiskur, S. L.; Anslyn, E. V. J. Am. Chem. Soc. 2004, 126, 6072-6077.

(9) For the differentiation of structurally similar analytes using a multicomponent IDA in combination with a neural network analysis see: (a) Wiskur S. L.; Floriano, P. N.; Anslyn, E. V.; McDevitt, J. T. Angew. Chem., Int Ed. 2003, 42, 2070-2072. (b) McCleskey, S. C.; Floriano, P. N.; Wiskur, S. L.; Anslyn, E. V.; McDevitt, J. T. Tetrahedron 2003, 59, 10089-10092.

(10) For IDAs in the context of a chip-based array see: McCleskey, S. C.; Griffin, M. J.; Schneider, S. E.; McDevitt, J. T.; Anslyn, E. V. J. Am Chem. Soc. 2003, 125, 1114-1115.

(11) Work directed towards the construction of IDA arrays based on molecularly imprinted polymers was recently reported: Greene, N. T.; Morgan, S. L.; Shimizu, K. D. Chem. Commun. 2004, 1172-1173.

(12) For reviews about sensor arrays, see: (a) Lavigne, J. J.; Anslyn, E. V Angew. Chem., Int. Ed. 2001, 40, 3118-3130. (b) Albert, K. J.; Lewis, N. S.; Schauer, C. L.; Sotzing, G. A.; Stizel, S. E.; Vaid, T. P.; Walt, D. R. Chem. Rev. 2000, 100, 2595-2626.

(13) For colorimetric sensor arrays based on metal-ligand interactions, see: (a) Suslick, K. S.; Rakow, N. A.; Sen, A. Tetrahedron 2004, 60, $11133-$ 11138. (b) Rakow, N. A.; Suslick, K. S. Nature 2000, 406, 710-713

(14) Severin, K.; Bergs, R.; Beck, W. Angew. Chem., Int. Ed. 1998, 37, 16351654.

(15) A behavior of this kind is expected for ligands, the metal-binding groups of which have a different $\mathrm{p} K_{\mathrm{a}}$.

(16) $\Delta A=A(\mathbf{1}+\mathbf{2}+$ amino acid $)-A(\mathbf{2})$

(17) The UV/vis absorption was measured at a fixed wavelength for each dye: 750 (2), $345(3)$, and $400 \mathrm{~nm}(\mathbf{4})$

(18) Jurs, P. C.; Bakken, G. A.; McClelland H. E. Chem. Rev. 2000, 100, $2649-2678$.

JA042363V 